\title{
BENAZEPRIL HYDROCHLORIDE LOADED NIOSOMAL FORMULATION FOR ORAL DELIVERY: FORMULATION AND CHARACTERIZATION
}

\author{
AMEERAH A. RADHI
}

Assistant Lecturer, Department of Pharmaceutics, College of Pharmacy, University of Al-Mustansiryah, Baghdad, Iraq Email: ameerahradhi@gmail.com

Received: 26 May 2018, Revised and Accepted: 23 Jun 2018

\section{ABSTRACT}

Objective: The objective of the present study was to formulate niosomal formulations of benazepril hydrochloride in an attempt to overcome the hurdles associated with it's poor oral absorption.

Methods: Nine formulations were prepared with various ratios of sorbitan monostearate (span 60), sorbitan monopalmitate (span 40) and polyoxyethylene 2 stearyl ether (brij 72) as non-ionic surfactants, cholesterol as a stabilizing agent and soya lecithin as a charge imparting agent. Then, they were characterized for vesicle size, polydispersity (PDI), entrapment efficiency (EE \%), release profile, zeta ( $\zeta$ ) potential and transmission electron microscopy (TEM).

Results: Niosomal formulations exhibited an efficient entrapment range between (80.4-97.8) percent, vesicles size analyses revealed the formation of homogenously dispersed vesicles having a size range of $(3.9 \pm 1.7-8.72 \pm 4.4)$ micrometers. The in vitro release studies revealed that all formulations displayed sustained release in comparison with the pure drug. Formulations prepared with span 60 and span 40 possessed adequate stability according to zeta potential analysis, whereas brij 72 failed the test and possessed inadequate zeta potential range. TEM images of the optimized formulations (F7 and F8) have confirmed the formation of vesicles with spherical shapes.

Conclusion: Based on the study results, niosomal formulations seem to be attractive alternatives to conventional delivery for benazepril hydrochloride.

Keywords: Benazepril hydrochloride, Niosomes, Oral delivery, Thin film hydration

(C) 2018 The Authors. Published by Innovare Academic Sciences Pvt Ltd. This is an open access article under the CC BY license (http://creativecommons.org/licenses/by/4.0/) DOI: http://dx.doi.org/10.22159/ijap.2018v10i5.27564

\section{INTRODUCTION}

Vesicular systems have drawn attention as promising carriers that are widely investigated for controlled delivery of pharmaceuticals to enhance their bioavailability, selectivity, and minimize toxicity. Due to their unique structure as a lamella consisting of amphiphiles, they can accommodate both the hydrophilic and hydrophobic molecules within their aqueous core and lipid bilayers, respectively. These comprise of liposomes, niosomes, ethosomes, transferosomes and bilosomes [1].

While liposomes require high formulation cost and are highly susceptible to oxidation. Niosomes, on the other hand, are cheap and stable over a longer period of time in different conditions. Niosomes are made up of non-ionic surfactants and cholesterol. Surfactants commonly employed include polyoxyethylene fatty acid esters (tweens), sorbitan fatty acid esters (spans), alkyl ethers, and polyoxyethylene alkyl ethers (brijs) [2]. Niosomal formulations are able to traverse the intestinal epithelium through different routes as transcellular, paracellular transport and/or nonspecific uptake mechanisms (by M-cells and intestinal epithelial cells). Therefore, they have been extensively studied in improving oral bioavailability of poorly absorbed drugs [3].

Benazepril hydrochloride is an angiotensin-converting enzyme inhibitor. It is used in the management of hypertension and heart failure. The problem with the drug is poor oral absorption (37\%) [4]. Consequently, this arises the need for developing novel vesicular carriers to improve it's oral bioavailability. The aim of the present work was to formulate niosomal formulations of benazepril hydrochloride using different nonionic surfactants, cholesterol as a membrane stabilizing agent and soya lecithin as a charge imparting agent. Formulations were in vitro

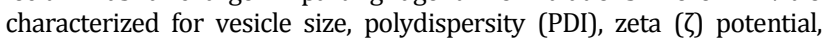
entrapment efficiency (EE \%) and release behaviour.

\section{MATERIALS AND METHODS}

\section{Materials}

Benazepril HCL and brij 72 (polyoxyethylene 2 stearylether) were obtained from Baoji Guokang Bio-Technology Co., Ltd, China. Cholesterol and soya lecithin were obtained from M/S Provizer Pharma, India. Span
60 (sorbitan monostearate) and span 40 (sorbitan monopalmitate) were obtained from Sinopharm Chemical Reagent Co., Ltd., China. Dialysis bags were obtained from Schuchardt München, Germany.

\section{Methodology}

\section{Preparation of niosomes}

Niosomal formulations were prepared using the conventional thin film hydration method. Firstly, surfactant and cholesterol in amounts given in table (1) were dissolved in $10 \mathrm{ml}$ chloroform and added into a 100-ml flask of the rotary evaporator (R-210, Buchi). Then, chloroform was allowed to evaporate under reduced pressure and gentle rotation in a water bath thermo-stated at $60 \pm 2{ }^{\circ} \mathrm{C}$ until observing a thin lipid layer. An aqueous phase containing $10 \mathrm{mg}$ benazepril HCL dissolved in $10 \mathrm{ml}$ distilled water was added to the lipid phase at atmospheric pressure under gentle rotation in a water bath at $60 \pm 2{ }^{\circ} \mathrm{C}$ for $60 \mathrm{~min}$, followed by sonication in a bath sonicator (SB 25-12 DTDN) for additional $60 \mathrm{~min}$. Afterwards, the obtained formulations were stored in $4{ }^{\circ} \mathrm{C}$ for further analysis [5].

\section{Characterization of benazepril hydrochloride niosomes}

Vesicle size and polydispersity index (PDI)

The prepared formulations were observed under an optical microscope (Novex, Holland) to confirm vesicles formation. Microphotographs were taken by a camera attached to the microscope. Then, further analysis using image $\mathrm{j}$ software was undertaken to measure the mean diameter and polydispersity index (PDI) for vesicles that lie within the micro size range [6]. Measurements were carried out in triplicate for each formulation and presented as the average \pm standard deviation (SD).

\section{Entrapment efficiency (EE \%)}

Niosomal formulations were centrifuged at 14000 round per minute (rpm) for $90 \mathrm{~min}$ at $4{ }^{\circ} \mathrm{C}$ in a cooling centrifuge (Hermle labortechnik, Germany) to separate the free drug from the entrapped drug. The obtained clear supernatant fraction was then analyzed spectrophotometrically at $241 \mathrm{~nm}$ [7]. 
The percent entrapment efficiency was calculated using the below equation [8]:
$\mathrm{EE} \%=\frac{\text { Total drug }- \text { free drug }}{\text { total drug }} * 100$

Table 1: The composition of niosomal formulations

\begin{tabular}{|c|c|c|c|c|c|c|}
\hline Formulation & Benazepril HCl & Span 60 & Span 40 & Brij 72 & Cholesterol & Soya lecithin \\
\hline F1 & $10 \mathrm{mg}$ & $400 \mathrm{mg}$ & & & $100 \mathrm{mg}$ & \\
\hline $\mathrm{F} 2$ & $10 \mathrm{mg}$ & & $400 \mathrm{mg}$ & & $100 \mathrm{mg}$ & \\
\hline F3 & $10 \mathrm{mg}$ & & & $400 \mathrm{mg}$ & $100 \mathrm{mg}$ & \\
\hline F4 & $10 \mathrm{mg}$ & $400 \mathrm{mg}$ & & & $400 \mathrm{mg}$ & \\
\hline F5 & $10 \mathrm{mg}$ & & $400 \mathrm{mg}$ & & $400 \mathrm{mg}$ & \\
\hline F6 & $10 \mathrm{mg}$ & & & $400 \mathrm{mg}$ & $400 \mathrm{mg}$ & \\
\hline F7 & $10 \mathrm{mg}$ & $400 \mathrm{mg}$ & & & $400 \mathrm{mg}$ & $50 \mathrm{mg}$ \\
\hline F8 & $10 \mathrm{mg}$ & & $400 \mathrm{mg}$ & & $400 \mathrm{mg}$ & $50 \mathrm{mg}$ \\
\hline F9 & $10 \mathrm{mg}$ & & & $400 \mathrm{mg}$ & $400 \mathrm{mg}$ & $50 \mathrm{mg}$ \\
\hline
\end{tabular}

Formulations (F1-F3), (F1-F6) and (F4-F9) were elaborated to investigate the impact of surfactant type, amount of cholesterol and inclusion of lecithin on the various properties of the prepared formulations, respectively.

\section{In vitro release studies}

Release studies were carried out for both pure benazepril hydrochloride and the loaded niosomal formulations. Each Formulation was instilled in a dialysis membrane bag with a molecular weight cut off (8000-12 000 KDa) and sealed from both sides [9]. It was then tied to the shaft of dissolution apparatus (Vanguard/USA) and immersed in $500 \mathrm{ml}$ of de-ionized water at constant temperature $37 \pm 0.5{ }^{\circ} \mathrm{C}$ and rotation speed of $50 \mathrm{rpm}$. Thereafter, Samples of $5 \mathrm{ml}$ were taken at predetermined intervals and replaced with fresh media so that the sink condition is maintained. Percentage drug released was assayed using a UV-Vis spectrophotometer (Shimadzu, UV-Vis 1650, Japan) at $241 \mathrm{~nm}$ [10]. Studies were carried out in triplicate for each formulation and presented as the average \pm standard deviation (SD).

\section{Zeta potential ( $\zeta$ potential)}

Zeta potential for all niosomal formulations was measured with zeta-sizer (Zeta Plus) (Brookhaven Instruments, USA) which has a sensitivity range from- 150 to +150 millivolt $(\mathrm{mV})$ and accuracy of $\pm 2 \%$. It is equipped with 35 milliwatt $(\mathrm{mW})$ solid state laser, red (660 nm wavelength) [11].

\section{Transmission electron microscopy (TEM)}

A drop of diluted specimens of the optimized formulations F7 and F8 was placed on the grid and then observed using CM 10 transmission electron microscope to confirm niosomes formation and examine their morphology. Samples were observed at an operating voltage of 80 kilovolts (KV) [12].

\section{Statistical analysis}

The obtained data were analyzed using the one-way analysis of variance $($ ANOVA) test. $(\mathrm{P}<0.05)$ was considered as an estimate of significance when evaluating the degree of differences between various formulations.

\section{RESULTS AND DISCUSSION}

\section{Preparation of niosomes}

Based on the collected data, It has been concluded that the type of surfactant, amount of cholesterol and inclusion of soya lecithin are influential factors that governs the vesicle size, poly-dispersity, entrapment efficiency and in vitro release profile.

\section{Vesicles size and polydispersity index (PDI)}

The measured vesicles diameters of all niosomal formulations are listed in the table (2). The results reveal that when other variables were fixed, the stearyl chain (C18) surfactants (span 60 and brij 72) produced significantly $(p<0.05)$ bigger vesicles than palmityl chain (C16) surfactant (span 40). This might be explained by the effect of the alkyl chain length. Longer alkyl chains produce wider bilayers; consequently, larger vesicles are attained. Similar findings were obtained with glimepiride niosomes [13].

The results also showed that increasing cholesterol content from $100 \mathrm{mg}$ to $400 \mathrm{mg}$ led to lowering vesicles size significantly $(\mathrm{p}<0.05)$. The intercalation of cholesterol within the bilayers enhances their hydrophobic nature, thereby decreasing water uptake and decreasing both the aqueous core and vesicle size [14].

On the other hand, the addition of soya lecithin produced significantly larger vesicles $(p<0.05)$ when comparing F7, F8 and F9 with F4, F5and F6, respectively. Soya lecithin is a charge inducing agent that contains phosphatidylcholine as a major component. It imparts a negative charge on the surface of the vesicle allowing more water entrapment within the aqueous core. Therefore, larger vesicles are formed [15]. Polydispersity index (PDI) is considered a measure of the degree of the homogeneity in vesicle size distribution within the prepared formulations. PDI value below 0.3 is considered as an indication for monodisperse systems according to the literature [16]. The calculated PDI for the niosomal formulations ranged between 0.09 and 0.34 .

Table 2: Entrapment efficiency\%, vesicle size, polysispersity and zeta potential of niosomal formulations

\begin{tabular}{|c|c|c|c|c|}
\hline Formulation & EE\% & Vesicle size \pm SD (micrometer)* & PDI & $\zeta$ potential(mV) \\
\hline F1 & 93.8 & $7.02 \pm 3.57$ & 0.26 & -39.14 \\
\hline $\mathrm{F} 2$ & 90.4 & $4.57 \pm 2.337$ & 0.26 & -42.68 \\
\hline F3 & 92.9 & $7.38 \pm 4.34$ & 0.34 & -12.22 \\
\hline F4 & 86.8 & $5.01 \pm 2.1$ & 0.17 & -45.14 \\
\hline F5 & 80.4 & $3.9 \pm 1.7$ & 0.19 & -35.03 \\
\hline F6 & 84.7 & $5.241 \pm 2.6$ & 0.24 & -12.93 \\
\hline F7 & 97.8 & $8.72 \pm 4.4$ & 0.25 & -32.13 \\
\hline F8 & 94.4 & $6.21 \pm 2.5$ & 0.16 & -45.91 \\
\hline F9 & 95.9 & $7.01 \pm 2.2$ & 0.09 & -20.12 \\
\hline
\end{tabular}

$*(n=3)$ (mean \pm standard deviation) 


\section{Entrapment efficiency (EE \%)}

The results of EE\% (table 2) revealed that formulations F1 (span 60) and F3 (brij 72) gave higher $(\mathrm{p}<0.05) \mathrm{EE} \%$ than F2 (span 40). This may be ascribed to the entrapment of the hydrophilic drug (benazepril $\mathrm{HCL}$ ) in the internal aqueous core of niosomes which is mainly affected by the length of the alkyl chain of the surfactant employed. These results are compatible with the vesicles diameters measurements where longer alkyl chain surfactants (span 60 and brij 72) produced bigger vesicles. As a result, provided more space for the trapped solute [17]

The increment of cholesterol content from $100 \mathrm{mg}$ in (F1, F2 and F3) to $400 \mathrm{mg}$ in (F4, F5 and F6) has led to significant lowering in EE\% $(\mathrm{p}<0.05)$. This might be due to the decrease in volume diameter [18].

The impact of charge inducing agent on EE\% was investigated by the inclusion of $50 \mathrm{mg}$ soya lecithin into formulations (F7, F8 and F9). As expected, EE\% was enhanced significantly $(\mathrm{p}<0.05)$ in these formulation as a result of their relatively large vesicles which allows for more solute entrapment [19]. Besides, it might be due to the electrostatic attractions between the cationic drug and the negatively charged vesicles. Similar observations were obtained in tamoxifen citrate loaded span-based nanovesicles [20].

\section{In vitro release studies}

All formulations showed sustained release when compared to a pure drug which exhibited percent release of $99.9 \%$ within 15 min (fig. 1). This might be due to the inherent nature of niosomes as a depot that encapsulate the drug and releases it in a controlled manner. Formulations F1, F2 and F3 were elaborated using span 60, span 40 and brij 72, along with cholesterol in ratio of (4:1) to investigate the impact of surfactant structure on the release profile from niosomal formulations. The release profile followed the trend span $60<$ span $40<$ brij 72 where span 60 formulation exhibited the slowest release rate $(p<0.05)$ among the other formulations. It has been previously reported that more tight and compact niosomes results from more hydrophobic span surfactants when hydrated in presence of cholesterol [21]. These findings agree with the previously reported results of paclitaxel niosomes [3].

Span 40 formulation exhibited a faster release rate $(\mathrm{p}<0.05)$ compared to span 60 . This can be explained by the fact that span 40 possess a shorter alkyl chain length and smaller vesicle diameter. Thus, a shorter diffusion path for benazepril HCL [22].

Even though brij 72 share the same alkyl group (stearyl) chain with span $60, F 3$ showed significantly faster $(\mathrm{p}<0.05)$ release rate than F1. This may be attributed to the long hydrophilic polyoxyethylene head group in brij 72 which might build looser bilayered vesicles facilitating the drug escape [23].

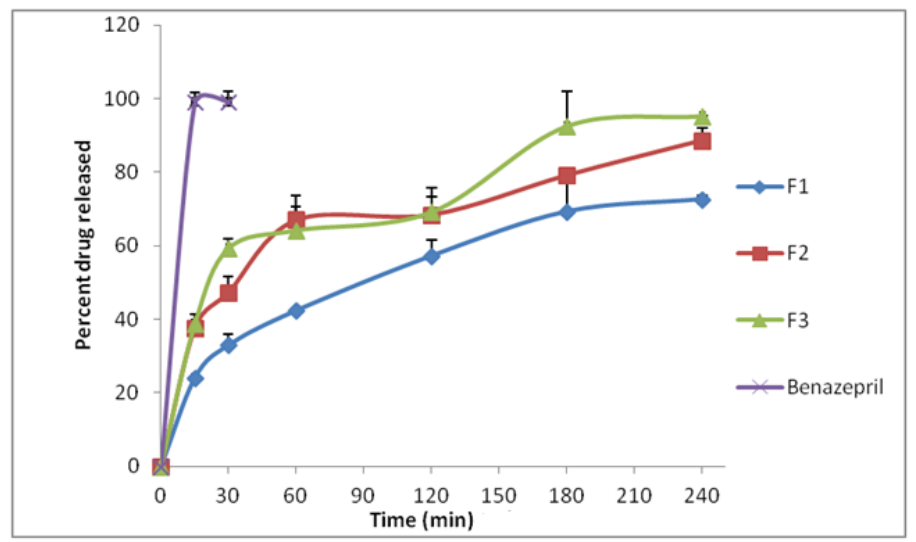

Fig. 1: Benazepril $\mathrm{HCl}$ release from formulations (F1-F3) and pure drug (n=3) (mean \pm standard deviation)

Increasing the amount of cholesterol from $100 \mathrm{mg}$ in F1, F2 and F3 to $400 \mathrm{mg}$ in F4, F5 and F6 while fixing the quantities of surfactants led to a profound retardation effect $(\mathrm{p}<0.05)$ on the drug release rate as shown in (fig. 2). Cholesterol was employed in this study as a stabilizing agent that strengthens the cohesion and membrane rigidity. Therefore; it decreased drug permeability across the bilayered vesicles [24].

The inclusion of soya lecithin in F7, F8 and F9 also decreased the release rate significantly $(p<0.05)$, as seen in (fig. 3$)$ in terms of increasing membrane stability and reduced leakage [25].

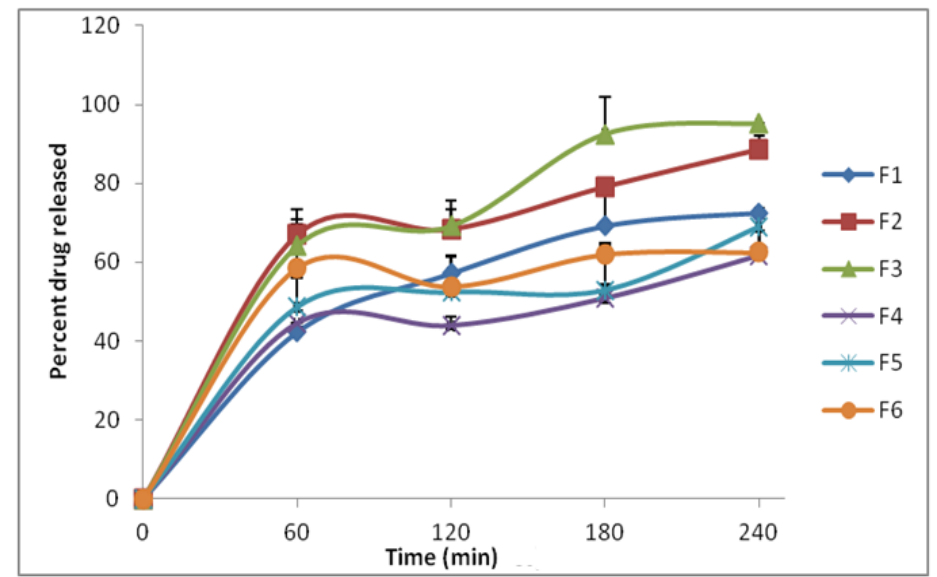

Fig. 2: Benazepril HCl release from formulations (F1-F6) (n=3) (mean \pm standard deviation) 


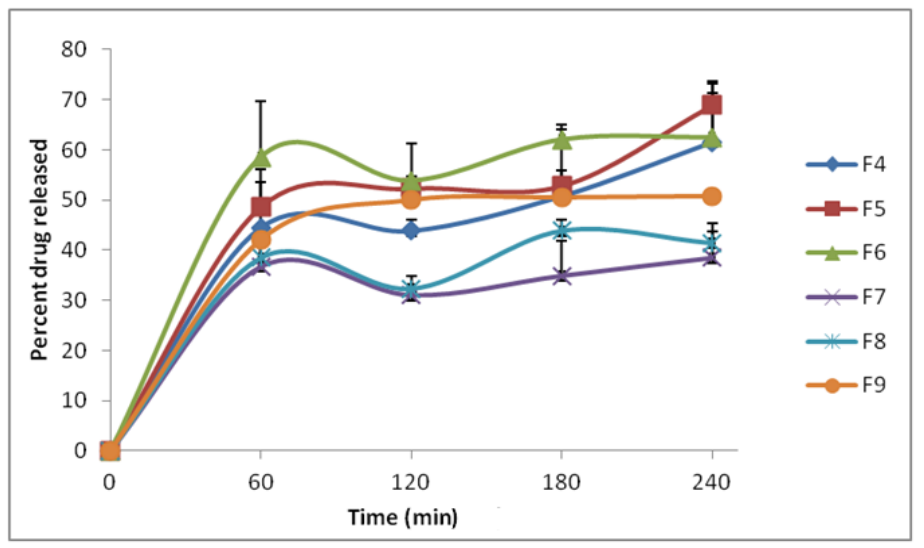

Fig. 3: Benazepril HCl release from formulations (F4-F9) $(\mathrm{n}=3)$ (mean \pm standard deviation)

Formulations F7, F8 and F9 exhibited the desired sustained release profile as they released only $38.4 \%, 41.4 \%$ and $50.8 \%$ respectively at the end of $4 \mathrm{~h}$. The least the drug released from the carrier vesicles, the higher encapsulated within to be absorbed at the absorption site in the gastrointestinal tract.

\section{Zeta potential ( $\zeta$ potential)}

Zeta potential analyses provide a measure to the stability of colloidal dispersions. It governs the degree of repulsion of similarly charged particles, thereby preventing their flocculation. It is reported that zeta potential value of -30 to- $60 \mathrm{mV}$ is favourable for the niosomal stability, but if the potential is reduced below- $30 \mathrm{mV}$, the particles may attract each other and aggregate eventually [26].

Zeta potential measurements shown in the table (2) clearly suggest that formulations prepared using span 60 and span 40 possess adequate stability with potential range between-32.13 to$45.91 \mathrm{mV}$,whereas all formulations prepared using brij 72 had inadequate zeta potential range between-12.22 and-20.12 $\mathrm{m} \mathrm{V}$.

Zeta potential measurements are directly related to the surface charge. Formulations (F1-F6) were prepared using non-ionic surfactants, yet they carry a negative charge due to adsorption of hydroxyl ions from aqueous medium [27].

Soya lecithin containing phosphatidylcholine as a major component was included in this study as a charge imparting agent to boost the niosomal stability. Obtained results revealed that addition of soya lecithin while fixing the quantities of both surfactant and cholesterol had increased the zeta potential from-35.03 in F5 to- $45.91 \mathrm{mV}$ in F8 and from-12.93 in $\mathrm{F} 6$ to- $20.12 \mathrm{mV}$ in $\mathrm{F} 9$. These findings are in agreement with clomipramine niosomes [28]. Fig. 4 depicts zeta potential analyses for F7 (A) and F8 (B) and F9 (C).

\section{Transmission electron microscopy (TEM)}

The obtained TEM images clearly elucidate the formation of spherically shaped vesicles with distinct boundaries, as observed in (fig. 5).

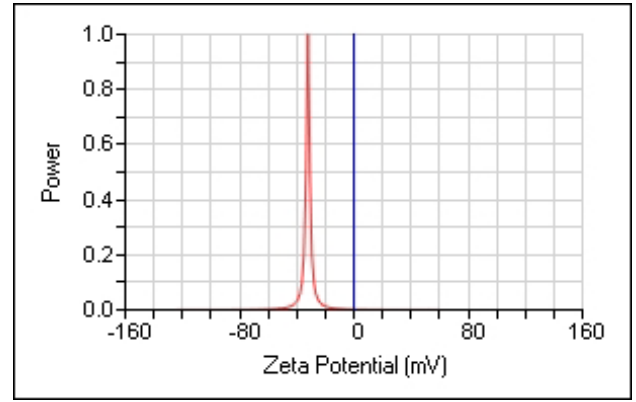

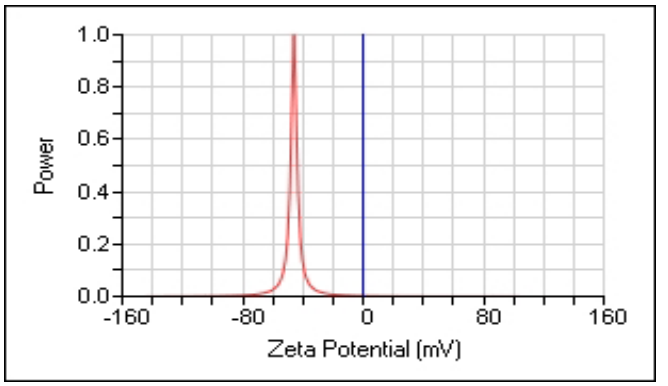

B

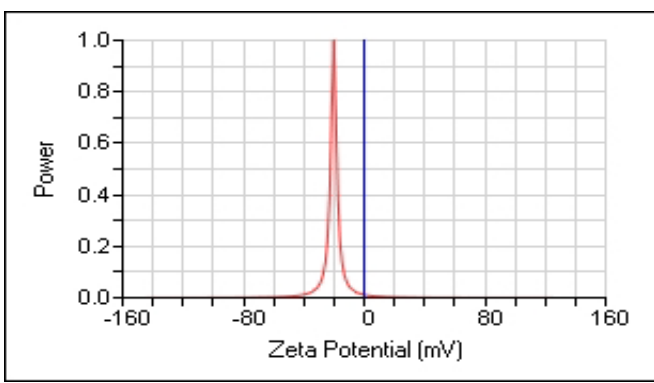

C

Fig. 4: Zeta potential analyses of F7 (A) and F8 (B) and F9 (C)

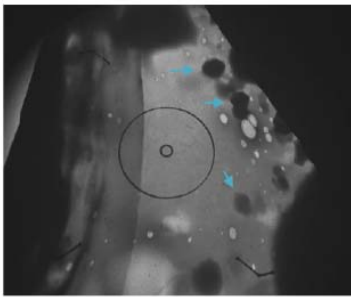

A

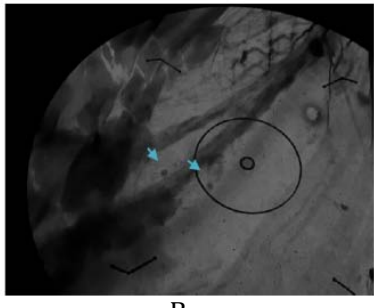

Fig. 5: TEM micrograghs of F7 (A) and F8 (B)

\section{CONCLUSION}

It can be concluded that benazepril HCL was successfully formulated in niosomal formulations. Among all formulations, F7 and F8 elaborated employing span 60 and span 40, respectively exhibit the desired properties with respect to size, PDI, EE\%, $\zeta$ potential and in vitro release profile. Thus, they might be employed as potential carriers of benazepril HCL. 


\section{ACKNOWLEDGMENT}

The author is deeply grateful for the support from Al-Mustansiriyah University (www. uomustansiriyah. edu. iq), Baghdad-Iraq. The author is also sincerely thankful to lecturer Dr. Masar Basim Mohsin Mohamed for her support during the study.

\section{AUTHOR CONTRIBUTION}

All the work have been carried out by me

\section{CONFLICT OF INTERESTS}

Declared none

\section{REFERENCES}

1. Mahale NB, Thakkar PD, Mali RG, Walunj DR, Chaudhari SR. Niosomes: novel sustained release nonionic stable vesicular systems-an overview. Adv Colloid Interface Sci 2012;183184:46-54.

2. Rai AK, Alam G, Singh AP, Verma NK. Niosomes: an approach to current drug delivery-a review. Int J Adv Pharm 2017;6:41-8.

3. Bayindir ZS, Yuksel N. Characterization of niosomes prepared with various nonionic surfactants for paclitaxel oral delivery. J Pharm Sci 2010;99:2049-60.

4. Sweetman SS. Martindale: the complete drug reference. $36^{\text {th }}$ ed. London: Pharmaceutical Press; 2009. p. 582.

5. Sharma Y, Kumar K, Padhy SK. Formulation and evaluation of atorvastatin calcium niosomes. Int J Life Sci Sci Res 2016;2:462-5.

6. Nadzir MM, Fen TW, Mohamed A, Hisham SF. Size and stability of curcumin niosomes from combinations of tween 80 and span 80. Sains Malays 2017;46:2455-60.

7. Vyshnavi V, Indira S, Srinivas P. Formulation and evaluation of nasal niosomal in situ gels of loratadine. Int J Pharm Sci Drug Res 2015;7:13-21.

8. Awad RS, Abdelwahed W, Bitar Y. Evaluating the impact of preparation conditions and formulation on the accelerated stability of tretinoin loaded liposomes prepared by the heating method. Int J Pharm Pharm Sci 2015;7:171-8.

9. Imran M, Shah MR, Ullah F, Ullah S, Elhissi AM, Nawaz W, et al. Sugar-based novel niosomal nanocarrier system for enhanced oral bioavailability of levofloxacin. Drug Delivery 2016;23: 3653-64.

10. The United States Pharmacopoeia (USP) 30, NF 25. USA: The United States Pharmacopeial Convention Inc; 2006.

11. Isnan AP, Jufri M. Formulation of niosomal gel containing green tea extract (Camellia Sinensis L. Kuntze) using thin-layer hydration. Int J Appl Pharm 2017;9 Suppl 1:38-43.

12. Alemi A, Reza JZ, Haghiralsadat F, Jaliani HZ, Karamallah MH, Hosseini SA, et al. Paclitaxel and curcumin coadministration in novel cationic pegylated niosomal formulations exhibit enhanced synergistic antitumor efficacy. J Nanobiotechnol 2018;16:28.

13. Mohsen AM, AbouSamra MM, ElShebiney SA. Enhanced oral bioavailability and sustained delivery of glimepiride via niosomal encapsulation: in vitro characterization and in vivo evaluation. Drug Dev Ind Pharm 2017;43:1254-64.

14. El-Laithy HM, Shoukry O, Mahran LG. Novel sugar esters proniosomes for transdermal delivery of vinpocetine: preclinical and clinical studies. Eur J Pharm Biopharm 2011;77:43-55.

15. Sezgin Bayindir Z, Antep MN, Yuksel N. Development and characterization of mixed niosomes for oral delivery using candesartan cilexetil as a model poorly water-soluble drug. AAPS PharmSciTech 2015;16:108-17.

16. Obeid MA, Gebril AM, Tate RJ, Mullen AB, Ferro VA. Comparison of the physical characteristics of monodisperse non-ionic surfactant vesicles (NISV) prepared using different manufacturing methods. Int J Pharm 2017;521:54-60.

17. Haoa YM, Li K. Entrapment and release difference resulting from hydrogen bonding interactions in niosome. Int J Pharm 2011;403:245-53.

18. Salih OS, Samein LH, Ali WK. Formulation and in vitro evaluation of rosuvastatin calcium niosomes. Int J Pharm Pharm Sci 2013;5 Suppl 4:525-35.

19. Alsarra IA, Bosela AA, Ahmed SM, Mahrous GM. Proniosomes as drug carrier for transdermal delivery of ketorolac. Eur J Pharm Biopharm 2005;59:485-90.

20. Kassem MA, Megahed MA, Abu Elyazid SK, Abd-Allah FI, Abdelghany TM, Al-Abd AM, et al. Enhancing the therapeutic efficacy of tamoxifen citrate loaded span-based nano-vesicles on human breast adenocarcinoma cells. AAPS PharmSciTech 2018;19:1529-43.

21. Girigoswami A, Das S, De S. Fluorescence and dynamic light scattering studies of niosomes membrane mimetic systems. Spectrochim Acta Part A 2006;64:859-66.

22. Ruckmani K, Sankar V. Formulation and optimization of zidovudine niosomes. AAPS PharmSciTech 2010;11:1119-27.

23. Yang DB, Zhu JB, Huang ZJ, Ren HX, Zheng ZJ. Synthesis and application of poly (ethylene glycol)-cholesterol (Chol-PEGm) conjugates in the physicochemical characterization of nonionic surfactant vesicles. Colloids Surf B 2008;63:192-9.

24. Madni A, Rahim MA, Mahmood MA, Jabar A, Rehman M, Shah H, et al. Enhancement of dissolution and skin permeability of pentazocine by proniosomes and niosomal gel. AAPS PharmSciTech 2018;19:1544-53.

25. El-ridy MS, Badawi AA, Safar MM, Mohsen AM. Niosomes as a novel pharmaceutical formulation encapsulating the hepatoprotective drug silymarin. Int J Pharm Pharm Sci 2012;4:549-59.

26. Sinko PJ, Colloidal dispersions. In: Martin's physical pharmacy and pharmaceutical sciences.6th ed. Philadelphia: Lippincott Williams and Wilkins; 2011. p. 732.

27. Shiny A, Toomu MC, Dhurke RK. Enhanced dermal delivery of nadifloxacin using liposomes. Int J Appl Pharm 2016;8:53-9.

28. Mohawed OAM, El-ashmoony MM, Elgazayerly ON. Niosomeencapsulated clomipramine for transdermal controlled delivery. Int J Pharm Pharm Sci 2014;6:567-75. 